\title{
Cephalometric evaluation of surgical mandibular advancement
}

\author{
Eloísa Marcantônio Boeck(a) \\ Mayury Kuramae ${ }^{(a)}$ \\ Nádia Lunardi(a) \\ Ary dos Santos-Pinto(b) \\ Renato Mazzonetto(c)
}

\footnotetext{
(a) Professor, Department of Orthodontics, Hermínio Ometto University Center, Araras University (UNIARARAS), Araras, SP, Brazil.

(b) Professor, Department of Orthodontics, Faculdade de Odontologia de Araraquara, UNESP - Univ Estadual Paulista, Araraquara, SP, Brazil.

(c) Professor, Department of Surgery, Piracicaba Dental School, University of Campinas (UNICAMP), Piracicaba, SP, Brazil.
}

\begin{abstract}
The treatment of Class II adult individuals with mandibular deficiency has been the combination of orthodontic treatment and orthognathic surgery. Therefore, a study was conducted in which cephalometric analysis was used to evaluate the influence of dentoalveolar decompensation in Class II patients submitted to orthodontic and surgical treatment for mandibular advancement, by bilateral osteotomy of the mandibular ramus. A sample of 15 leukoderma adult female patients were selected and three cephalometric radiographs of each patient, taken before the orthodontic treatment, before surgery and after at least 6 months postoperatively, were analyzed in a total of 45 roentgenograms. The tracings were made by the manual method and the points were digitalized using software. The results showed that values of SNB increased from 75.6 to $78.6^{\circ}$. The measures BNP and PGNP were reduced from -12.7 to $-7.7 \mathrm{~mm}$ and -12.7 to $-6.6 \mathrm{~mm}$, respectively. For ANB there was a reduction of $3.23^{\circ}$ (from $8.1^{\circ}$ to $4.9^{\circ}$ ). Likewise, the values of AOBO were diminished by $6.3 \mathrm{~mm}$ (from 7.6 to $1.3 \mathrm{~mm}$ ), and in the values of OJ there was a reduction of $5.7 \mathrm{~mm}$ (from 9 to $3.3 \mathrm{~mm}$ ). It was concluded that the pre-surgical orthodontic treatment promoted minimal and variable dental and skeletal changes in the final result. The surgical treatment caused significant skeletal changes, especially in the measurements related to the mandible (SNB, BNP, PGNP and SNPM) or indirectly to it (ANB, AOBO and OJ).
\end{abstract}

Descriptors: Orthodontics; Retrognathism; Mandibular advancement.

\section{Introduction}

Dentoskeletal deformities are known to cause severe functional and esthetic complaints in patients. Combined orthodontic and surgical treatment is the best choice for adult individuals, since it results in better esthetic appearance and function, followed by long term stability. ${ }^{1,2,3,4}$ Compensatory treatment can lead to occlusal and muscular changes, dysfunctional problems, and TMJ disorders. ${ }^{5}$

The diagnosis and treatment plan for patients with dentoskeletal deformities should be carried out individually, with cephalometric, occlusal and facial analyses, which take into account the position of the maxillary and mandibular incisors on the basal bone. ${ }^{6,7}$

The Class II skeletal deformity results from an increased sagittal gap between the maxilla and the mandible, regardless of the relationship between the maxillary and mandibular molars. Such skeletal dysfunction
Received for publication on Jan 14, 2010 Accepted for publication on Mar 22, 2010 
can be due to maxillary protrusion or mandibular deficiency, the latter being found more frequently than the former. ${ }^{8}$ The clinical findings are: chin retraction, shortening of the submental region and closing of the mento-cervical angle. Further findings are eversion of the lower lip, exposure of the maxillary incisors and deepening of the mentolabial sulcus. Moreover, individuals with Class II division 1 dental-relationships with mandibular deficiency present an open mandibular plane, decreased SNB angle, increased ANB angle and positive AO-BO. Sagittal compensations show well placed or slightly protrused maxillary incisors and mandibular incisors invariably protrused and labially inclined, which decreases the overjet and disguises the skeletal discrepancy.

When the pre-surgical dental decompensation is not carried out, the amount of skeletal correction that can be accomplished surgically is severely limited, and the esthetic and functional results will fall below the ideal standards..$^{1,2,3}$ The larger the incisor decompensation, the further the mandible can be advanced, and the better the esthetic result will be. Therefore, during orthodontic preparation, the anterior teeth are displaced so that the skeletal discrepancy is accentuated and the incisors are ideally placed on their apical basis, regardless of their interdental relationship. ${ }^{2}$

It has been extensively reported that stable results are directly related to proper surgical procedures and orthodontic preparation, which should include dental decompensation. Through cephalometric analysis, the aim of our investigation was to evaluate the influence of the dental and skeletal changes due to surgical-orthodontic treatment in individuals with Class II malocclusion and mandibular deficiency, who underwent orthognathic surgery consisting of bilateral sagittal osteotomy for mandibular advancement.

\section{Material and Methods}

A total of 15 leukoderma, adult, female, Brazilian individuals, with Class II malocclusion and mandibular deficiency, were selected from the Center for Research and Treatment of Dentofacial Deformities - CEDEFACE (Araraquara, SP, Brazil). The research project was approved by the Research Ethics Committee of the Piracicaba Dental School/UNICAMP (protocol number 156/2002).

The selection criteria were as follows: skeletal Class II pattern (Table 1); non growth potential (mean initial age of 28.3); without history of congenital syndrome and defect; Edgewise technique orthodontic treatment; mandibular advancement surgery with no associated genioplasty (bilateral mandibular sagittal osteotomy technique); $;^{9,10}$ use of internal rigid immobilization and lateral cephalometric radiographic evaluation at stages: $t_{1}$ (pre orthodontic treatment), $t_{2}$ (immediately prior to surgery), and $\mathrm{t}_{3}$ (minimum of 6 months after surgery).

Identification of the cephalometric points (Figure 1) at stages $t_{1}, t_{2}$ and $t_{3}$ was carried out by the manual method, by only one operator with the light box, on 8 " x 10" ultraphan paper (GAC International Inc, Bohemia, NY, USA) and a $0.3 \mathrm{~mm}$ pencil (Pentel, Tokyo, Japan). The cephalograms were digitized by software 2.02 Dentofacial Planner Plus (First Canadian Place, Toronto, ON, Canada).

The dental and skeletal changes were measured through the projection of the cephalometric points onto the horizontal and vertical reference lines, which represented the $\mathrm{X}$ and $\mathrm{Y}$ Cartesian coordinates, respectively at $t_{1}, t_{2}$ and $t_{3}$. The horizontal line ( $\mathrm{X}$ axis) was determined from the Sela point (S), with a downward inclination of $7^{\circ}$ in relation to the $\mathrm{S}-\mathrm{N}$ line. The vertical line ( $\mathrm{Y}$ axis), was determined from point $S$, perpendicular to the $\mathrm{X}$ axis (Figure 2).

For the statistical analysis the following were used: linear regression, Student's- $t$ test and analysis of variance $(\mathrm{p}<0.05)$.

Table 1 - Characterization according to the facial skeletal pattern.

\begin{tabular}{l|r|r}
\hline & Mean & S.D. \\
\hline SNA $\left(^{\circ}\right)$ & 83.78 & 3.45 \\
\hline SNB $\left(^{\circ}\right)$ & 75.66 & 3.33 \\
\hline ANB $\left(^{\circ}\right)$ & 8.13 & 1.76 \\
\hline AOBO $(\mathrm{mm})$ & 7.60 & 4.31 \\
\hline ANP $(\mathrm{mm})$ & 0.73 & 3.45 \\
\hline BNP $(\mathrm{mm})$ & -12.74 & 5.97 \\
\hline PGNP $(\mathrm{mm})$ & -12.71 & 7.00 \\
\hline
\end{tabular}




\section{Results}

Stepwise linear regression realized one step to express the QAM (magnitude of the mandibular advancement) due to the alterations in the measurements obtained from the total treatment, which resulted in the following equation (Table 2):

$$
\mathrm{QAM}=8.87-1.16 \times \mathrm{SNPM}
$$

Therefore, the magnitude of the mandibular advancement was significantly influenced by the changes in the SNPM measurements. It was observed that only $26.9 \%$ of the QAM variation was explained by this final equation, however, the equation was very well adjusted to the coordinate plane points (QAM, SNPM), because the $\mathrm{F}_{0}=6.14$ value was significant $(\mathrm{p}<0.05)$.

The application of the linear multiple regression to express the QAM measurement due to the orthodontic treatment changes was such that no alteration in the cephalometric measurements between these stages were incorporated into this pattern; that is, the estimate process of the inclination interception standards, known as stepwise, did not realize any step.

The stepwise linear multiple regression was performed in three steps to express the QAM measurement due to the surgical treatment changes. The same statistical procedure was performed to express the QAM due to the measurement alterations that occurred within these times. Therefore, the magnitude of the mandibular advancement QAM was significantly influenced by the alterations of the ANB, ANP and OB. It was observed that this final equation explained $96.3 \%$ of the QAM variation and that

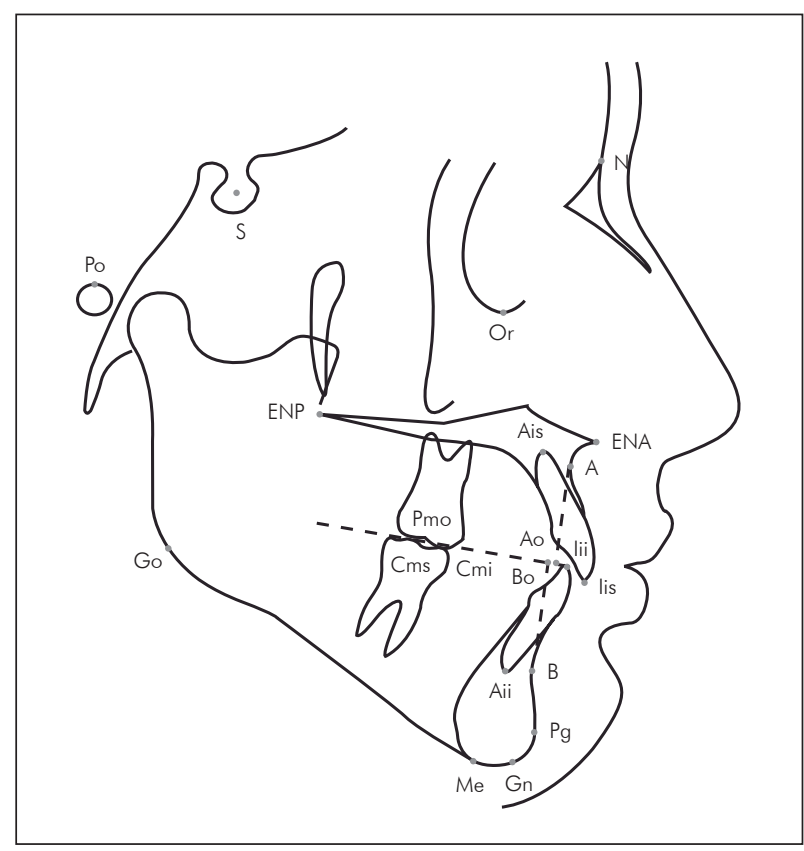

Figure 1 - Cephalogram with the evaluated points.

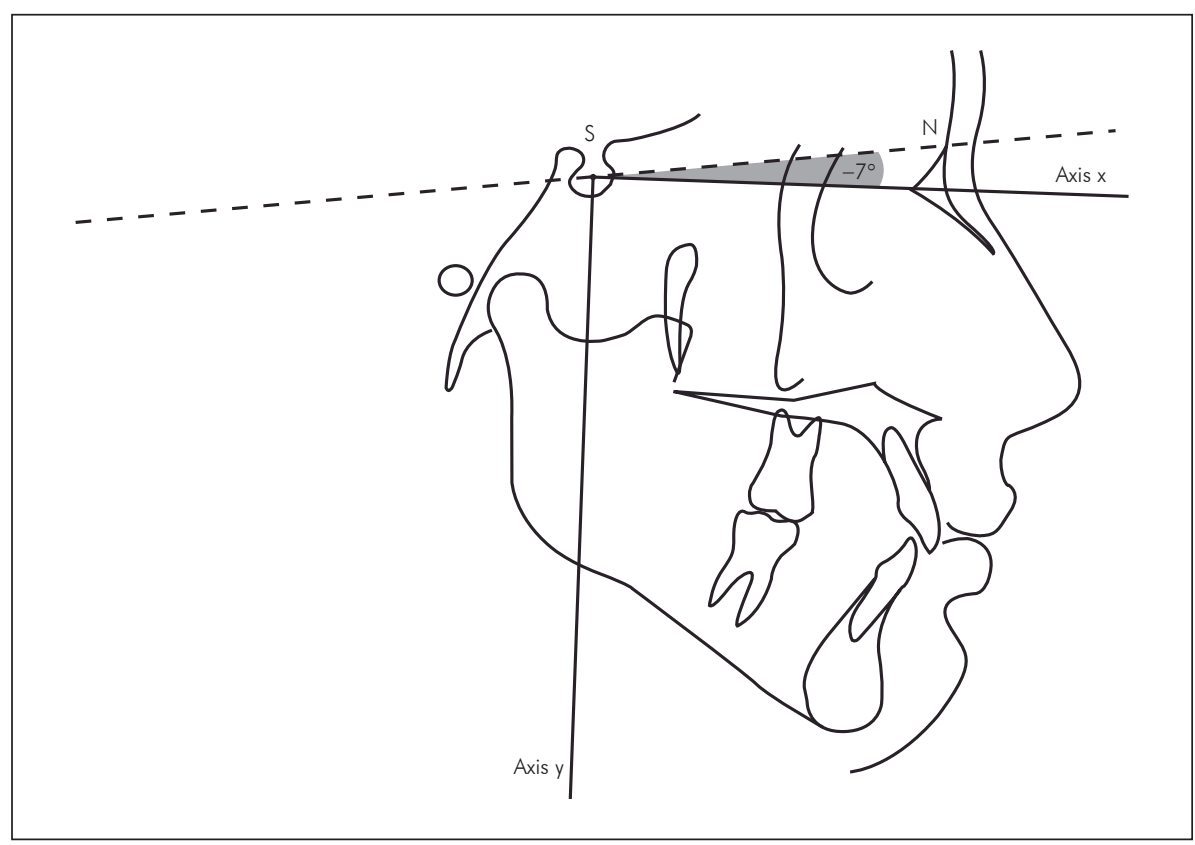

Figure 2 - Projection of the cephalometric points onto the horizontal and vertical reference lines. 
Table 2 - Coefficient with standard error for QAM, values of $t_{0}, F_{0}, R^{2}$ and $p$.

\begin{tabular}{c|c|c|c|c|c|c|c}
\hline \multicolumn{7}{c}{ Total changes } \\
\hline & Coef & SE & $t_{0}$ & $\mathrm{p}<$ & $\mathrm{F}_{0}$ & $\mathrm{P}<$ & $\mathrm{R}_{2}$ \\
\hline Constant & $\beta_{0}=8.87$ & 1.12 & $7.932^{*}$ & 0.001 & $6.14^{*}$ & 0.028 & 26.9 \\
\hline SNPM & $\beta_{1}=-1.16$ & 0.47 & $-2.478^{*}$ & 0.028 & & & \\
\hline \multicolumn{7}{c}{ Orthodontic changes } \\
\hline No analyzed measurements were included \\
\hline Constant & $\beta_{0}=0.18$ & 0.70 & 0.252 ns & 0.342 & $124.2^{*}$ & 0.001 & 96.3 \\
\hline ANB & $\beta_{1}=-2.98$ & 0.19 & $-15.319^{*}$ & 0.001 & & & \\
\hline ANP & $\beta_{2}=2.89$ & 0.24 & $12.227^{*}$ & 0.001 & & & \\
\hline OB & $\beta_{3}=0.32$ & 0.12 & $2.789^{*}$ & 0.018 & & & \\
\hline
\end{tabular}

*significant value. ns: non significant.

Table 3 - Frequency, mean, standard deviation and group of equal means, according to measurements.

\begin{tabular}{|c|c|c|c|c|c|c|c|}
\hline Measurements & Stage & Mean & S.D. & Measurements & Stage & Mean & S.D. \\
\hline \multirow{3}{*}{ SNA $\left(^{\circ}\right)$} & $t_{1}$ & 83.7 & 3.456 & \multirow{3}{*}{$\mathrm{OB}(\mathrm{mm})$} & $t_{1}$ & 3.7 & 4.087 \\
\hline & $t_{2}$ & 83.2 & 3.027 & & $t_{2}$ & 3.5 & 2.925 \\
\hline & $t_{3}$ & 83.5 & 3.458 & & $t_{3}$ & 2.2 & 1.471 \\
\hline \multirow{3}{*}{ SNB $\left(^{\circ}\right)$} & $t_{1}$ & 75.6 & 3.333 & \multirow{3}{*}{ ANP $(\mathrm{mm})$} & $t_{1}$ & 0.7 & 3.455 \\
\hline & $\mathrm{t}_{2}$ & 75.3 & 3.362 & & $t_{2}$ & 0.2 & 3.103 \\
\hline & $t_{3}$ & 78.6 & 3.541 & & $t_{3}$ & 0.5 & 3.521 \\
\hline \multirow{3}{*}{ ANB $\left(^{\circ}\right)$} & $t_{1}$ & 8.1 & 1.766 & \multirow{3}{*}{$\mathrm{BNP}(\mathrm{mm})$} & $t_{1}$ & -12.7 & 5.979 \\
\hline & $t_{2}$ & 7.9 & 1.581 & & $t_{2}$ & -13.4 & 6.096 \\
\hline & $t_{3}$ & 4.9 & 2.441 & & $t_{3}$ & -7.7 & 6.226 \\
\hline \multirow{3}{*}{$\mathrm{AOBO}(\mathrm{mm})$} & $t_{1}$ & 7.6 & 4.311 & \multirow{3}{*}{ PGNP (mm) } & $t_{1}$ & -12.7 & 7.004 \\
\hline & $t_{2}$ & 6.6 & 2.702 & & $t_{2}$ & -13.3 & 7.398 \\
\hline & $t_{3}$ & 1.3 & 2.700 & & $t_{3}$ & -6.6 & 7.465 \\
\hline \multirow{3}{*}{ ISNA ( $\left.{ }^{\circ}\right)$} & $t_{1}$ & 16.2 & 10.515 & \multirow{3}{*}{ ISSN $\left(^{\circ}\right)$} & $t_{1}$ & 99.9 & 11.121 \\
\hline & $t_{2}$ & 15.4 & 5.461 & & $t_{2}$ & 98.7 & 5.867 \\
\hline & $t_{3}$ & 14.9 & 6.457 & & $t_{3}$ & 98.6 & 6.126 \\
\hline \multirow{3}{*}{ IS-NA (mm) } & $t_{1}$ & 2.8 & 3.422 & \multirow{3}{*}{ IIPM ( $\left.{ }^{\circ}\right)$} & $t_{1}$ & 90.1 & 9.858 \\
\hline & $t_{2}$ & 2.2 & 2.568 & & $t_{2}$ & 91.3 & 5.867 \\
\hline & $t_{3}$ & 1.5 & 2.670 & & $t_{3}$ & 89.3 & 5.373 \\
\hline \multirow{3}{*}{ IINB $\left(^{\circ}\right)$} & $t_{1}$ & 24.5 & 9.599 & \multirow{3}{*}{$\operatorname{SNPP}\left({ }^{\circ}\right)$} & $t_{1}$ & 7.8 & 2.713 \\
\hline & $t_{2}$ & 25.8 & 5.908 & & $t_{2}$ & 7.3 & 2.992 \\
\hline & $t_{3}$ & 26.0 & 5.187 & & $t_{3}$ & 7.6 & 2.843 \\
\hline \multirow{3}{*}{ II-NB (mm) } & $t_{1}$ & 4.9 & 2.705 & \multirow{3}{*}{ SNPM $\left({ }^{\circ}\right)$} & $t_{1}$ & 38.7 & 4.941 \\
\hline & $t_{2}$ & 4.7 & 2.236 & & $t_{2}$ & 39.1 & 5.604 \\
\hline & $t_{3}$ & 5.2 & 2.023 & & $t_{3}$ & 38.2 & 6.156 \\
\hline \multirow{3}{*}{ OJ (mm) } & $t_{1}$ & 9.0 & 3.615 & & & & \\
\hline & $t_{2}$ & 8.6 & 2.385 & & & & \\
\hline & $t_{3}$ & 3.3 & 0.639 & & & & \\
\hline
\end{tabular}


Table 4 - Mean, standard deviation and p values according to measurement alteration due to the period.

\begin{tabular}{|c|c|c|c|c|c|c|c|c|c|}
\hline \multirow[b]{2}{*}{ Measurement } & \multicolumn{3}{|c|}{ Orthodontic } & \multicolumn{3}{|c|}{ Surgical } & \multicolumn{3}{|c|}{ Total } \\
\hline & mean & S.D & $p<$ & mean & S.D. & $p<$ & mean & S.D. & $p<$ \\
\hline SNA $\left({ }^{\circ}\right)$ & -0.5 & 1.4 & 0.202 & 0.2 & 1.1 & 0.402 & -0.2 & 1.7 & 0.604 \\
\hline SNB $\left(^{\circ}\right)$ & -0.2 & 0.8 & 0.223 & 3.2 & 1.6 & 0.001 & 2.9 & 1.6 & 0.001 \\
\hline ANB $\left(^{\circ}\right)$ & -0.2 & 1.7 & 0.624 & -2.9 & 1.4 & 0.001 & -3.2 & 2.1 & 0.001 \\
\hline $\mathrm{AOBO}(\mathrm{mm})$ & -0.9 & 3.0 & 0.231 & -5.2 & 2.5 & 0.001 & -6.2 & 3.3 & 0.001 \\
\hline ISNA $\left(^{\circ}\right)$ & -0.7 & 11.7 & 0.808 & -0.5 & 3.7 & 0.600 & -1.2 & 12.9 & 0.711 \\
\hline IS-NA (mm) & -0.5 & 3.6 & 0.536 & -0.6 & 1.4 & 0.109 & -1.2 & 4.2 & 0.275 \\
\hline IINB $\left({ }^{\circ}\right)$ & 1.2 & 9.0 & 0.613 & 0.2 & 4.2 & 0.192 & 1.4 & 10.8 & 0.605 \\
\hline II-NB (mm) & -0.2 & 2.7 & 0.778 & 0.4 & 1.3 & 0.192 & 0.2 & 2.9 & 0.735 \\
\hline OJ (mm) & -0.4 & 3.0 & 0.559 & -5.2 & 2.1 & 0.001 & -5.6 & 3.5 & 0.001 \\
\hline $\mathrm{OB}(\mathrm{mm})$ & -0.1 & 2.2 & 0.757 & -1.3 & 2.4 & 0.060 & -1.3 & 3.4 & 0.114 \\
\hline ANP $(\mathrm{mm})$ & -0.4 & 1.3 & 0.205 & 0.2 & 1.1 & 0.372 & -0.1 & 1.7 & 0.678 \\
\hline $\mathrm{BNP}(\mathrm{mm})$ & -0.6 & 1.6 & 0.118 & 5.7 & 2.9 & 0.001 & 5.0 & 2.8 & 0.001 \\
\hline PGNP (mm) & -0.6 & 1.9 & 0.219 & 6.7 & 3.7 & 0.001 & 6.0 & 3.3 & 0.001 \\
\hline ISSN $\left({ }^{\circ}\right)$ & -1.2 & 11.4 & 0.675 & -0.1 & 3.6 & 0.900 & -1.3 & 12.7 & 0.682 \\
\hline IIPM ( $\left.{ }^{\circ}\right)$ & 1.2 & 9.7 & 0.644 & -1.9 & 4.2 & 0.089 & -0.7 & 11.4 & 0.797 \\
\hline $\operatorname{SNPP}\left({ }^{\circ}\right)$ & -0.4 & 1.8 & 0.344 & 0.3 & 2.2 & 0.608 & -0.1 & 0.9 & 0.508 \\
\hline SNPM $\left({ }^{\circ}\right)$ & 0.4 & 1.9 & 0.428 & -0.8 & 1.4 & 0.040 & -0.4 & 2.1 & 0.481 \\
\hline
\end{tabular}

it was very well adjusted to the point coordinates on the hyperplane (QAM, ANB, ANP, OB), because the $\mathrm{F}_{0}=124.2$ value was significant $(\mathrm{p}<0.05)$.

Table 3 shows the mean measurements and Table 4 shows means according to measurement alteration due to the period.

\section{Discussion}

Combined orthognathic surgery and orthodontic treatment have been considered very satisfactory for improving the function and facial esthetics of individuals with dentoskeletal deformities. ${ }^{5,6,11,12}$ This study shows that the esthetic improvement was due mostly to the post surgical changes of the SNB, BNP and PGNP, all of which characterize mandibular advancement. For Class II anomalies with mandibular deficiency, individuals treated with the combined approach have shown more pronounced changes than those treated with orthodontic camouflage. Moreover, according to previous studies, results of the combined orthosurgical technique were more stable $^{13}$ and the TMJ dysfunction rate was lower. ${ }^{6}$
Orthodontic camouflage can cause excessive inclination of the mandibular incisors, followed by periodontal injury in the long term. ${ }^{14}$

The mean initial measurements of the study group confirmed skeletal Class II, with ANB 8.1 $( \pm 1.7)$ and $\mathrm{AOBO} 7.6 \mathrm{~mm}( \pm 4.3)$; good maxillacranial base relationship $83.7^{\circ}( \pm 3.4)$ and retrognathic mandible $75.6^{\circ}( \pm 3.3)$. Individuals with mandibular deficiency with Class II dental relationship showed decreased SNB, increased ANB and positive AOBO. ${ }^{9}$ Measurements after the surgical-orthodontic treatment confirmed better maxilla-mandible relationship related to a reduction in the ANB of $4.9^{\circ}( \pm 2.4)$ and $\mathrm{AOBO}$ of $1.3 \mathrm{~mm}( \pm 2.7)$, which are values similar to those found in skeletal Class I. The SNA value remained practically the same, $83.5^{\circ}$ $( \pm 3.4)$, and the SNB increased to $78.6^{\circ}( \pm 3.5)$, which indicated anterior displacement of the mandible (Table 3).

The overall changes showed that the variation of the mandibular plane inclination (SNPM) greatly influenced the degree of mandibular advancement: 
the higher the opening of the mandibular plane, the smaller mandibular advancement observed at the end of treatment. This influence, however, accounted for only $26.9 \%$ of the overall variation, with a moderate correlation between the mandibular advancement and the SNPM. All the other measurements showed no significant changes and were discarded. The changes that occurred after orthodontic treatment showed no significant influence on the magnitude of the mandibular advancement (Table 2).

Post surgical changes showed that the mandibular advancement was significantly influenced by the altered maxillary-mandibular relationship, confirmed by ANB. The larger the initial ANB, the greater was the mandibular advancement after surgery. The maxilla position (ANP) and the overbite also influenced the magnitude of advancement, since the larger was the maxillary retrusion and the smaller the overbite, the shorter was the advancement observed (Table 2).

The overall changes in Table 4 showed that the only dental measurement subject to significant alteration at this stage was the overjet (OJ). In terms of skeletal variables, the measurements of $\mathrm{SNB}, \mathrm{ANB}$, AOBO, BNP and PGNP were significant.

The wide variation in inclination (high standard deviation) found for the changes in the mandibular and maxillary incisors with the orthodontic treatment evidence the efforts to decompensate preexisting dentoalveolar inclination in this first phase of the whole treatment. The mean variation of the mandibular incisor was $1.2^{\circ}$ buccally, but the variation of \pm 9.7 , obtained by inclination movements of $10.9^{\circ}$ buccally and of $8.5^{\circ}$ lingually (in $67 \%$ of the sample) regions, shows an attempt to obtain proper inclination for the surgical mandibular advancement. According to the ISSN measurements, the maxillary incisors had mean variation values of $1.2^{\circ}$ $( \pm 11.4)$, which indicated inclinations of up to $10.1^{\circ}$ buccally and \pm 12.7 lingually in $67 \%$ of the cases.

Such findings correspond to previous studies ${ }^{6,7}$ which consider the maxillary and mandibular incisor inclinations in relation to their cranial bases to be of great importance for the diagnosis and treatment plan of individuals with dentoskeletal deformities, along with the facial and occlusal analysis.
Also in agreement with findings that suggested that the goal of the standard presurgical orthodontic procedures should be the alignment and leveling of the maxillary and mandibular teeth and correction of the vertical and sagittal positions of the incisors, in attempt to reestablish their proper angulation and inclination. ${ }^{14}$ Such procedures should free the surgical movement of dental interferences, so that the cranial bases can be placed in a proper Class I relationship.

After surgery, the SNB, ANB, AOBO, BNP, PGNP, SNPM and OJ measurements underwent significant changes, which influenced the magnitude of mandibular advancement (Tables 2 and 4). Significant reductions of $2.9^{\circ}( \pm 1.4)$ for the ANB, and $5.2^{\circ}( \pm 2.1)$ for the overjet were observed. The ANP and the overbite did not present significant changes, with reductions of only $0.2^{\circ}( \pm 1.1)$ and $1.3^{\circ}( \pm 2.4)$, respectively. Authors reported $5 \mathrm{~mm}$ forward and downward movements of the $\mathrm{B}$ point, and a reduction of $3^{\circ}$ for ANB after mandibular advancement surgery with associated mentoplasty. ${ }^{15}$ According to their study, the higher were the initial values for the $\mathrm{ANB}$, the greater was its influence on the improvement in profile esthetics of the surgery.

The data showed that the SNA, ISNA, IS-NA, IINB, II-NB, OB, ANP, ISSN, IIPM, SNPP and SNPM (Table 3) had constant mean values and did not change significantly throughout stages $t_{1}$ to $t_{3}$; during this period the measurement values significantly increased for the SNB, BNP and PGNP, and decreased for the AOBO, ANB and OJ.

The maxillary incisor dental relationship (ISNA), which was initially $16.2^{\circ}( \pm 10.5)$, changed to $14.9^{\circ}$ $( \pm 6.4)$, an alteration of $1.3^{\circ}$. The maxillary incisor inclination in relation to the cranial base (ISSN) changed from $99.99^{\circ}( \pm 11.1)$, initially, to $98.6^{\circ}$ $( \pm 6.1)$. The maxillary incisor protrusion (IS-NA) also showed alteration of $1.3 \mathrm{~mm}$ moving from $2.8 \mathrm{~mm}( \pm 3.4)$ at $\mathrm{t}_{1}$, to $1.5 \mathrm{~mm}( \pm 2.6)$ at $\mathrm{t}_{3}$ (Table $3)$.

The mandibular incisor protrusion (II-NB) shifted from $4.9 \mathrm{~mm}( \pm 2.7)$ to $5.2 \mathrm{~mm}( \pm 2)$. The mandibular incisor inclination values (IINB) rose from $24.5^{\circ}( \pm 9.5)$ to $26^{\circ}( \pm 5.1)$. However, with values initially of $90.1^{\circ}( \pm 9.8)$, and finally of $89.3^{\circ}( \pm 5.3)$, 
the IIPM showed no variation. Since the mandibular advancement affects the NB plane inclination, the IINB measurement could also have been affected. Therefore, through the analysis of the IIPM measurement, which better expresses the mandibular incisor inclination, no alteration was observed (Table 3).

There was a decrease from $9 \mathrm{~mm}( \pm 3.6)$ to $3.3 \mathrm{~mm}( \pm 0.6)$ in the OJ, and from $3.7 \mathrm{~mm}( \pm 4.0)$ to $2.2 \mathrm{~mm}( \pm 1.4)$ in the OB. In a 5 -year-follow-up study it was reported that surgically treated individuals had twice as much overjet than those treated nonsurgically; while their overbite findings were similar for both groups. ${ }^{16}$ On the other hand, they observed a large reduction in overjet and improvement in the soft tissue, skeletal and dental patterns. ${ }^{11}$

The measurements for the ANP showed small alteration between the initial and final stages of the treatment, $\mathrm{t}_{1}=0.7 \mathrm{~mm}( \pm 3.4)$ and $\mathrm{t}_{3}=0.5 \mathrm{~mm}$ $( \pm 3.5)$, which indicated the stability of the maxilla and emphasized that the overall changes were exclusively due to the position of the mandible. The position of the mandible in relation to the $\mathrm{N}$ - perpendicular to the Frankfurt plane (BNP) - in the initial stage of the treatment was $-12.7 \mathrm{~mm}( \pm 5.9)$, which indicated evident retraction of the mandible at this stage. Values of $-7.7 \mathrm{~mm}( \pm 6.2)$ showed mandible protrusion of $5 \mathrm{~mm}$ after treatment. The PGNP measurements followed those of the BNP, since both points are located in the anterior portion of the mandible and use the same measurement reference plane. The PGNP varied from $-12.7 \mathrm{~mm}( \pm 7)$ to $-6.6 \mathrm{~mm}$ $( \pm 7.4)$, a mandibular advancement of $6.1 \mathrm{~mm}(\mathrm{Ta}-$ ble 3). Following mandibular surgery, alterations of $7 \mathrm{~mm}$ for the $\mathrm{B}$ point and of $8.5 \mathrm{~mm}$ for the $\mathrm{PG}^{17}$ were reported. Others found a mean advancement of $5.4 \mathrm{~mm}$, with less than $5 \%$ of recurrence. ${ }^{2}$

\section{References}

1. Sinclair PM. Orthodontic considerations in adult surgical orthodontic cases. Dent Clin North Am. 1988 Jul;32(3):50928.

2. Vig KD, Ellis III E. Diagnosis and treatment planning for the surgical-orthodontic patient. Clin Plast Surg. 1989 Oct;16(4):645-58.
The maxilla inclination in relation to the palatine plane (SNPP) showed small alteration, from $7.8^{\circ}( \pm 2.7)$ to $7.6^{\circ}( \pm 2.8)$. After the advancement, the SNPM values moved from $38.7^{\circ}( \pm 4.9)$ to $38.2^{\circ}$ $( \pm 6.1)$. These results suggested that the orthodontic mechanics and the surgical procedures did not affect the maxilla. However, the SNPM change was significant, which suggested the occurrence of mandibular rotation after the advancement (Table 3).

The significant changes in the inclinations of the incisors showed that the dental decompensation due to the orthodontic procedures was found to be variable in our sample. Dental compensations can be detected in three planes: sagittal, vertical and transversal. Teleradiography, on the other hand, can only afford sagittal and vertical evaluation of the anterior teeth. Therefore, it is important to emphasize that the functional and esthetic improvements found in our sample may have been influenced by the transversal decompensation and/or sagittal and vertical alterations that occurred in the posterior portion of the dental arches, since it is known that elimination of the dental compensations facilitates correction of the skeletal deformity. ${ }^{2}$

\section{Conclusions}

The dental and skeletal changes due to pre-surgical orthodontic treatment were variable; surgical treatment caused significant skeletal changes, especially in the SNB, BNP, PGNP and SNPM measurements (directly related to the mandible), as well as in those indirectly related to it (ANB, $\mathrm{AOBO}$ and $\mathrm{OJ}$ ); dental inclinations were variable and did not affect the magnitude of the mandibular advancement; and SNPM, ANB, ANP and OB were the variables which most significantly influenced the magnitude of the mandibular advancement.

3. Neeley WW 2nd. Dolce C. Hatch JP, Van Sickels JE, Rugh JD. Relationship of body mass index to stability of mandibular advancement surgery with rigid fixation. Am J Orthod Dentofacial Orthop. 2009 Aug;136(2):175-84.

4. Kitahara T, Nakasima A, Kurahara S, Shiratsuchi Y. Hard and soft tissue stability of orthognathic surgery. Angle Orthod. 2009 Jan;79(1):158-65. 
5. Gunsolus BR. Case Report CB - Surgical vs nonsurgical treatment in the nongrowing patient. Angle Orthod. 1989 Dec;59(4):305-10.

6. Epker BN, Fish LC. The surgical-orthodontic correction of mandibular deficiency. Part II. Am J Orthod. 1983 Dec;84(6):491-507.

7. Epker BN, Stella JP, Fish LC, Dentofacial deformities-integrated orthodontic and surgical correction. 2ed. St Louis: Mosby; 1995. 1802 p.

8. McNamara Jr JA, A method of cephalometric evaluation. Am J Orthod. 1984 Dec;86(6):449-69.

9. Trauner R, Obwegeser HL. The surgical correction of mandibular prognathism and retrognathia with consideration of genioplasty. Part I. Oral Surg Oral Med Oral Pathol. 1957 Sept;10(1):677-89.

10. Epker BN. Modifications in the sagittal osteotomy of the mandible. J Oral Surg. 1977 Feb;35(2):157-9.

11. Proffit WR. Phillips C. Douvartzidis N. A comparison of outcomes of orthodontic and surgical-orthodontic treatment of class II malocclusion in adults. Am J Orthod Dentofacial Orthop. 1992 Jun;101(6):556-65.
12. Tucker MR. Orthognathic surgery versus orthodontic camouflage in the treatment of mandibular deficiency. J Oral Maxillofac Surg. 1995 May;53(5):572-78.

13. Stoelinga PJ, Leenen RJ. Class II anomalies: a coordinated approach to the management of skeletal, dental, and soft tissue problems. J Oral Surg. 1981 Nov;39(11):827-41.

14. McNeill RW, West RA. Severe mandibular retrognathism: orthodontic versus surgical orthodontic treatment. Am J Orthod. 1977 Aug;72(2):176-82

15. Shelly AD, Southard TE, Southard KA, Casko JS, Jakobsen JR, Fridrich KL et al. Evaluation of profile esthetic change with mandibular advancement surgery. Am J Orthod Dentofacial Orthop. 2000 Jun;117(6):630-7.

16. Mihalik CA, Proffit WR, Phillips C, Long-term follow-up of class II adults treated with orthodontic camouflage: a comparison with orthognathic surgery outcomes. Am J Orthod Dentofacial Orthop. 2003 Mar;123(3):266-78.

17. Poulton DR, Ware WH, Increase in mandibular and chin projection with orthognathic surgery. Am J Orthod. 1985 May;87(5):363-76. 